\title{
DFT Study on the Different Oligomers of Glycerol (n=1-4) in Gas and Aqueous Phases
}

\author{
Younes Valadbeigi and Hossein Farrokhpour* \\ Department of Chemistry, Isfahan University of Technology, Isfahan, 84156-83111, Iran. \\ E-mail: farrokhphossein@gmail.com
}

(Received September 3, 2013; Accepted October 29, 2013)

\begin{abstract}
Since a glycerol molecule has three active sites, two $\alpha$ and one $\beta$ hydroxyl groups; it undergoes condensation by releasing water molecules to produce linear, nonlinear and heterocyclic oligomers. The Gibbs free energy $(G)$, enthalpy $(H)$ and internal energy (E) of 7 diglycerol, 15 triglycerol and 23 tetraglycerol isomers were calculated at B3LYP level of theory using $6-311++\mathrm{G}(\mathrm{d}, \mathrm{p})$ basis set, in both gas and aqueous phases. Linear oligomers, $\alpha \alpha$-diglycerol, $\alpha \alpha$, $\alpha \alpha$-triglycerol and $\alpha \alpha, \alpha \alpha, \alpha \alpha$-tetraglycerol, were found to be the most stable oligomers in aqueous phase. It was found that the stability of cyclic oligomers decreases as the size of their rings increases. Cyclic oligomers are produced by dehydration of the acyclic ones which is an endothermic reaction while its $\Delta \mathrm{G}$ is negative. The dehydration reaction is less endothermic in aqueous phase.
\end{abstract}

Key words: Glycerol, Oligomerization, Dehydration reaction, Density functional theory, Cyclic isomers

\section{INTRODUCTION}

Glycerol is an important chemical compound which has applications in food industry, pharmaceutical and personal care preparations. It is the backbone of triglycerides molecules which are the main components of animal fats and vegetable oils. ${ }^{1,2}$ In addition, glycerol is a base chemical for production of ample of valuable products in chemical industries including production of propylene glycol by selective hydrogenolysis, formation of acrolein by dehydration, Syngas by glycerol reforming, production of propane-1,3-diol during fermentation, oligomerization or polymerization, and so on. ${ }^{2-7}$

Oligomerization of the glycerol and the physical and chemical properties of its oligomers have been well studied by several researchers. ${ }^{2,8}$ It is found that the hydrophilic property of low oligomers is more than that for higher ones; therefore the low oligomers have a better solubility in polar solvents such as water. ${ }^{2}$ Diglycerol, triglycerol and tetraaglycerol are the low oligomers which are liquid, syrup-like and crystalline solid, respectively. ${ }^{2}$ Diglycerol has three linear and three cyclic isomers. Since glycerol has three reactive sites, two $\alpha$ and one $\beta$ hydroxyl groups, the three linear isomers of diglycerols are $\alpha \alpha$-, $\alpha \beta$ - and $\beta \beta$-diglycerol. Further condensation of the linear diglycerols produces cyclic diglycerols. ${ }^{2,9,10}$ Several methods have been proposed to lab-scale synthesis of pure diglycerol. ${ }^{8,11-13}$ However, oligomerization of glycerol is a way to produce diglycerol and the other oligomers. Olygo- merization of glycerol takes place using both homogeneous ${ }^{9,14}$ and heterogeneous ${ }^{15}$ catalysts where the latter catalysts are mainly acidic and basic zeolites. It is proposed that homogenous acid-catalyzed oligomerization of glycerol is an $\mathrm{SN} 1$ type reaction and proceeds through the formation of carbocation by splitting a water molecule from protonated glycerol. ${ }^{9}$ In the other hand, base-catalyzed oligomerization follows an SN2 type path. ${ }^{16}$

Medeiros et al. ${ }^{14}$ studied acid-catalyzed oligomerization of glycerol by electospray mass spectrometry and reported that in the initial stage of reaction, glycerin converts to diglycerol, then by consuming of diglycerol other larger oligomers (triglycerol and tetraglycerol) are produced. In addition, they detected compound formed by the dehydration of such primary oligomers. These dehydrated oligomers are a mixture of cyclic and unsaturated acyclic compound.

Theoretical studies on the oligomers structures of glycerol are rare and there are some studies on the role of surface basicity and acidity on the olygomerization of glycerol on metal oxides. ${ }^{16}$ Considering the above explanations, design of glycerol reactions in chemical industries needs some thermodynamic data about the glycerol and its olygomers and the stability of their structures. In this work, we study, theoretically, oligomerization of glycerol, catalyzed by acid and base, and calculate Gibbs free energy, enthalpy and internal energy for different isomers of diglycerol, triglycerol and tetraglycerol including cyclic and acyclic oligomers using density functional theory. In addition, 
condensation of acyclic diglycerols and triglycerols to corresponding cyclic compounds is investigated.

\section{COMPUTATIONAL DETAIL}

Since density functional theory (DFT) methods with a large and reasonable basis set can give reliable thermodynamic properties for systems included hydrogen bonding, ${ }^{17,18}$ the B3LYP as a DFT method was selected in this work. Large basis set, $6-311++\mathrm{G}(\mathrm{d}, \mathrm{p})$, used for the DFT calculations which involves polarization and diffuse functions for hydrogen and non-hydrogen atoms. Solvent (water) was modeled using Tomasi's polarized continuum model $(\mathrm{PCM})^{19}$ at the B3LYP level of theory. All calculations were performed using Gaussian 09 quantum chemistry package. ${ }^{20}$

\section{RESULTS AND DISCUSSION}

Protonation of glycerol is the first step of the homogeneous acid-catalyzed oligomerization. ${ }^{2}$

$$
\mathrm{Gly}+\mathrm{H}^{+} \rightarrow \mathrm{GlyH}^{+}
$$

The proton affinity values were obtained by calculating the change of enthalpy for reaction (1), where Gly presents the glycerol molecule. The enthalpy of $\mathrm{H}^{+}$was computed equal to 0.00236 Hartree which is equals to $5 / 2 R T$, in gas phase.

Glycerol molecule has three reactive sites to accept a proton, two $\alpha$ sites and one $\beta$ site. Reactions A-I and A-II in Fig. 1(a) present different paths to protonation of glycerol molecule. Since proton affinity is $-\Delta H$ of protona- tion of a molecule in the gas phase, the glycerol has two different proton affinity values (Table 1$)$. The protonated glycerol molecules release water molecules to produce cationic species (A-III and A-IV reactions in Fig. 1(a)). Each cationic intermediate reacts with a glycerol molecule through $\alpha$ or $\beta$ site to form different acyclic diglycerol molecules (A-V, A-VI, A-VII and A-VIII reactions in Fig. 1(a)). Fig. 2 shows optimum structures of the three acyclic diglycerol molecules.

In the base-catalyzed glycerol dimerization, a proton is separated from the glycerol by a hydroxide ion (B-I and B-II reactions in Fig. 1(b)) and two different anionic intermediates are produced. Each anionic de-protonated glycerol reacts with a new glycerol and three different acyclic diglycerol molecules are produced (B-III, B-IV, B-V and B-VI reactions in Fig. 1(b)). The optimum structures of the three acyclic diglycerol molecules are shown in Fig. 2.

The glycerol molecule has two proton affinity values of 807.41 and $836.17 \mathrm{~kJ} / \mathrm{mol}$ which are corresponding to $\alpha$ and $\beta$ protonation, respectively. These values show that protonation tendency of the glycerol molecule from $\beta$ site is more than $\alpha$ site. The difference in the proton affinity values probably pertains to the electron donor activity of carbon atoms in the $\alpha$ and $\beta$ sites; namely, when the glycerol molecule protonated from the $\alpha$ site only one carbon atom stabilize the positive charge of the proton while in the case of $\beta$ site, accommodation of the positive charge is easier. The protonation reaction in the gas phase is more thermodynamically desirable than that in aqueous phase; because the proton is hydrated and becomes stable in the aqueous phase; hence its tendency to react with the glycerol (a)<smiles>OCC(O)CO</smiles>

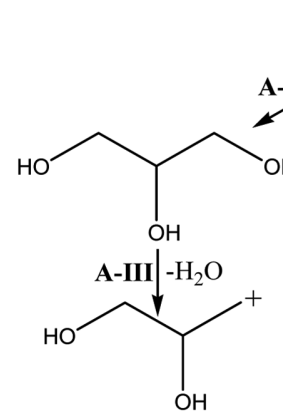

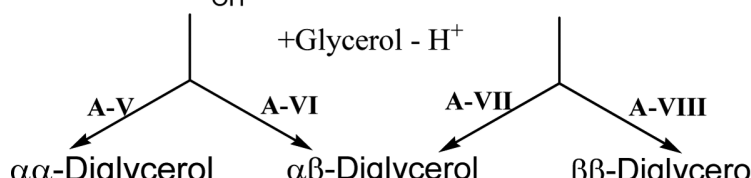

(b)<smiles>OCC(O)CO</smiles>

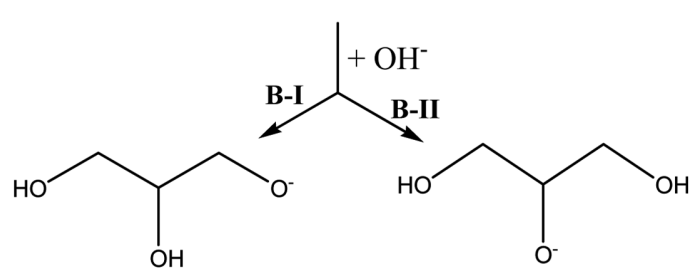

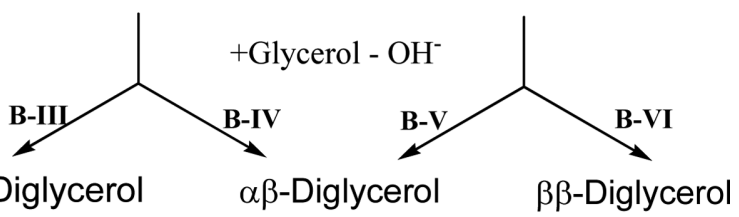

Figure 1. Homogeneous (a) acid- and (b) base-catalyzed dimerization of glycerol. 
Table 1. The enthalpies $(\Delta \mathrm{H})$ and Gibbs free energies $(\Delta \mathrm{G})$ of acid- and base-catalyzed dimerization of glycerol shown in fig.1.

\begin{tabular}{lcrcc}
\hline \multirow{2}{*}{ Reaction } & \multicolumn{2}{c}{ Gas phase } & \multicolumn{2}{c}{ Aqueous phase } \\
\cline { 2 - 5 } & $\Delta \mathrm{H}(\mathrm{kJ} / \mathrm{mol})$ & $\Delta \mathrm{G}(\mathrm{kJ} / \mathrm{mol})$ & $\Delta \mathrm{H}(\mathrm{kJ} / \mathrm{mol})$ & $\Delta \mathrm{G}(\mathrm{kJ} / \mathrm{mol})$ \\
\hline $\mathrm{Gly}^{+} \mathrm{H}^{+} \rightarrow \mathrm{GlyH}^{+}(\alpha$-protonated $)$ & -807.41 & -775.61 & -588.51 & -556.15 \\
$\mathrm{Gly}^{+} \mathrm{H}^{+} \rightarrow \mathrm{GlyH}^{+}(\beta$-protonated $)$ & -836.17 & -801.60 & -600.57 & -564.99 \\
$\mathrm{GlyH}^{+}(\alpha$-protonated $) \rightarrow \mathrm{C}_{3} \mathrm{H}_{5}(\mathrm{OH})_{2}^{+}(\alpha$-dehydrated $)+\mathrm{H}_{2} \mathrm{O}$ & +8.30 & -40.27 & -20.52 & -58.92 \\
$\mathrm{GlyH}^{+}(\beta$-protonated $) \rightarrow \mathrm{C}_{3} \mathrm{H}_{5}(\mathrm{OH})_{2}^{+}(\beta$-dehydrated $)+\mathrm{H}_{2} \mathrm{O}$ & -8.32 & -54.71 & -39.85 & -85.48 \\
$\mathrm{C}_{3} \mathrm{H}_{5}(\mathrm{OH})_{2}^{+}(\alpha$-dehydrated $)+\mathrm{Gly} \rightarrow \alpha \alpha$-diglycerol $+\mathrm{H}^{+}$ & +812.21 & +831.12 & +604.65 & +624.67 \\
$\mathrm{C}_{3} \mathrm{H}_{5}(\mathrm{OH})_{2}^{+}(\alpha$-dehydrated $)+\mathrm{Gly} \rightarrow \alpha \beta$-diglycerol $+\mathrm{H}^{+}$ & +817.29 & +842.33 & +610.75 & +637.00 \\
$\mathrm{C}_{3} \mathrm{H}_{5}(\mathrm{OH})_{2}^{+}(\beta$-dehydrated $)+\mathrm{Gly} \rightarrow \alpha \beta$-diglycerol $+\mathrm{H}^{+}$ & +862.53 & +882.76 & +642.14 & +663.55 \\
$\mathrm{C}_{3} \mathrm{H}_{5}(\mathrm{OH})_{2}^{+}(\beta$-dehydrated $)+\mathrm{Gly} \rightarrow \beta \beta$-diglycerol $+\mathrm{H}^{+}$ & +872.52 & +893.98 & +653.33 & +678.83 \\
$\mathrm{Gly}^{+} \mathrm{OH}{ }^{-} \rightarrow \mathrm{C}_{3} \mathrm{H}_{5}(\mathrm{OH})_{2} \mathrm{O}^{-}(\alpha$-deprotonated $)+\mathrm{H}_{2} \mathrm{O}$ & -55.77 & -61.70 & -0.70 & -2.54 \\
$\mathrm{Gly}+\mathrm{OH}$ & -161.39 & -25.58 & -26.32 \\
$\mathrm{C}_{3} \mathrm{H}_{5}(\mathrm{OH})_{2} \mathrm{O}^{-}(\alpha$-deprotonated $)+\mathrm{Gly} \rightarrow \alpha \alpha$-diglycerol $+\mathrm{OH}^{-}$ & +68.56 & +88.15 & -3.70 & +3.30 \\
$\mathrm{C}_{3} \mathrm{H}_{5}(\mathrm{OH})_{2} \mathrm{O}^{-}(\alpha$-deprotonated $)+\mathrm{Gly} \rightarrow \alpha \beta$-diglycerol $+\mathrm{OH}^{-}$ & +73.96 & +76.94 & +2.39 & +15.62 \\
$\mathrm{C}_{3} \mathrm{H}_{5}(\mathrm{OH})_{2} \mathrm{O}^{-}(\beta$-deprotonated $)+\mathrm{Gly} \rightarrow \alpha \beta$-diglycerol $+\mathrm{OH}^{-}$ & +179.42 & +187.83 & +27.27 & +39.40 \\
$\mathrm{C}_{3} \mathrm{H}_{5}(\mathrm{OH})_{2} \mathrm{O}^{-}(\beta$-deprotonated $)+$ Gly $\rightarrow \beta \beta$-diglycerol $+\mathrm{OH}^{-}$ & +189.26 & +199.04 & +38.46 & +54.68 \\
\hline & & &
\end{tabular}

molecules is decreased. The same fact is true about hydroxide ion and its stability in the aqueous phase is more than that in the gas phase.

Deprotonation of glycerol from $\beta$-site take places easier than that for $\alpha$ site in the base-catalyzed oligomerization; because the stability of the produced anion is more than that produced by $\alpha$-deprotonation. This stability decreases the reactivity of the $\beta$-deprotonated molecules to take apart in dimerization reaction.

Also, the final reactions in Fig. 1 which result in formation of diglycerols are competitive reactions. Comparison of Gibbs free energies of the A-V, A-VI, A-VII and AVIII show that formation of $\alpha \alpha$-diglycerol is thermodynamically favorite than formation of $\alpha \beta$ - and $\beta \beta$-diglycerol. To find the reason of this phenomenon, the structures of the three diglycerol molecules are investigated. Fig. 2 shows optimum structures of the acyclic diglycerol.
From the thermodynamic data reported in Table 2 it is found that the $\alpha \alpha$-diglycerol is the most stable and the $\beta \beta$ diglycerol is the most non-stable among the acyclic dimers of glycerol. Since the numbers of the hydrogen bonds in the three diglycerols is the same, the difference in their stabilities can be attributed to spatial structure and atomatom repulsion. The $\alpha \alpha$-diglycerol has an expanded and linear structure while $\beta \beta$-diglycerol has a compressed structure whose atoms are very close to each other. Therefore, the latter structure suffers from intramolecular repulsion.

The acyclic diglycerols undergo dehydration to produce cyclic ones. ${ }^{14}$ Fig. 3 shows optimum structures of four cyclic diglycerols with hexagonal, heptagonal and octagonal rings (D1-D4 structures). The internal energy (E), enthalpy $(\mathrm{H})$ and Gibbs free energy $(\mathrm{G})$ of the heterocyclic and acyclic diglycerol at $298 \mathrm{~K}$ calculated in gas and aqueous phases are tabulated in Table 2. (a)

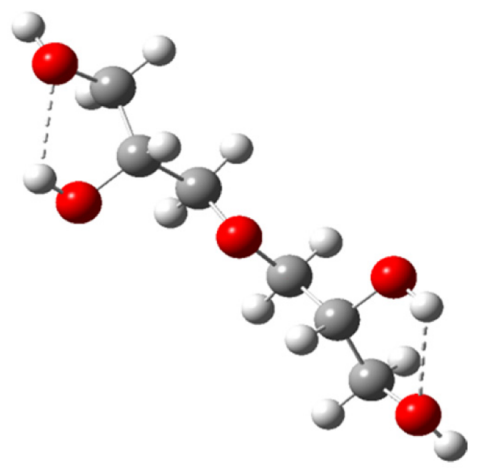

(b)

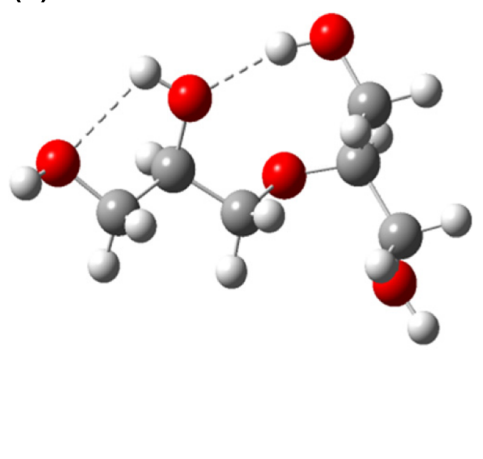

(c)

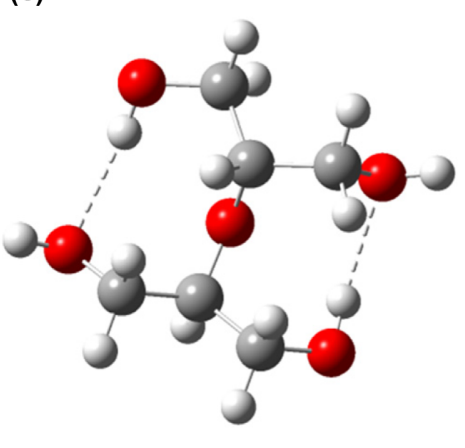

Figure 2. Optimum structures of acyclic diglycerol. (a) $\alpha \alpha-$, (b) $\alpha \beta$ - and (c) $\beta \beta$-diglycerols. Hydrogen bonds are indicated by dotted lines. 
Table 2. The enthalpy and Gibbs free energy of the acyclic and cyclic diglycerols relative to the $\alpha \alpha$-diglycerol and D4 conformers, respectively

\begin{tabular}{crrrr}
\hline \multirow{2}{*}{ Dimer } & \multicolumn{2}{c}{ Gas phase } & \multicolumn{2}{c}{ Aqueous phase } \\
\cline { 2 - 5 } & $\Delta \mathrm{H}(\mathrm{kJ} / \mathrm{mol})$ & $\Delta \mathrm{G}(\mathrm{kJ} / \mathrm{mol})$ & $\Delta \mathrm{H}(\mathrm{kJ} / \mathrm{mol})$ & $\Delta \mathrm{G}(\mathrm{kJ} / \mathrm{mol})$ \\
\hline$\alpha \alpha$-diglycerol & 0.00 & 0.00 & 0.00 & 0.00 \\
$\alpha \beta$-diglycerol & +8.04 & +13.85 & +8.59 & +14.81 \\
$\beta \beta$-diglycerol & +18.72 & +25.90 & +22.14 & +32.45 \\
D1 & +19.99 & +13.55 & +5.53 & +0.71 \\
D2 & +4.63 & -0.84 & +0.54 & -3.74 \\
D3 & +12.30 & +8.19 & +6.31 & +5.00 \\
D4 & 0.00 & 0.00 & 0.00 & 0.00 \\
\hline
\end{tabular}

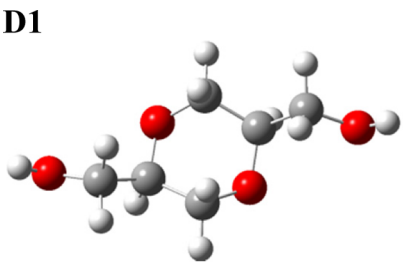

D2

D3

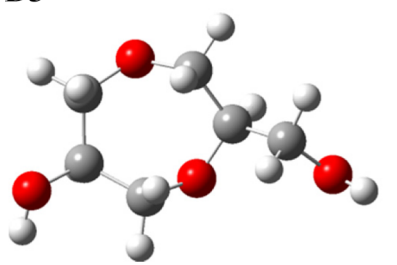

D4

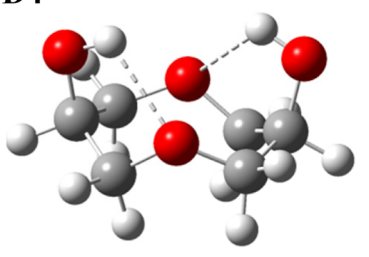

Figure 3. The structures of cyclic diglycerol optimized at B3LYP level using 6-311++G(d,p) basis set. Hydrogen bonding interactions are shown by dotted lines. The nomination (D1-D4) is arbitrary.

Among the cyclic diglycerols, D2 and D4 are more stable than D1 and D3 diglycerols. Optimum structures of D2 and D4 diglycerols show that their stability may be due to internal hydrogen bonding interactions where these interactions do not exist in D1 and D3 diglycerols. The hydrogen bonding interactions are shown by dotted lines in Fig. 3.

Further oligomerization of diglycerols results in production of seven acyclic triglycerols. The seven triglycerols are $\alpha \alpha, \alpha \alpha-, \alpha \alpha, \alpha \beta-, \alpha \alpha, \beta \alpha-, \alpha \alpha, \beta \beta-, \alpha \beta, \alpha \beta-, \beta \alpha, \alpha \beta-$ and $\beta \alpha, \beta \beta$-triglycerols which their structures are not shown. The enthalpy and Gibbs free energy of the heterocyclic and acyclic triglycerol at $298 \mathrm{~K}$ were calculated in gas and aqueous phases. Table 3 presents these energies relative to the $\alpha \alpha, \beta \beta$-triglycerol and T2, which are the most stable acyclic and cyclic conformers of triglycerl in the gas phase. All thermodynamic properties reported in Tables 2,3 and 5 are relative energies that have been calculated with respect to
Table 3. The enthalpy and Gibbs free energy of the acyclic and heterocyclic triglycerols relative to the $\alpha \alpha, \beta \beta$-triglycerol and T2 conformers, respectively

\begin{tabular}{crrrr}
\hline \multirow{2}{*}{ trimer } & \multicolumn{2}{c}{$\mathrm{Gas}$ phase } & \multicolumn{2}{c}{ Aqueous phase } \\
\cline { 2 - 5 } & $\Delta \mathrm{H}(\mathrm{kJ} / \mathrm{mol})$ & $\Delta \mathrm{G}(\mathrm{kJ} / \mathrm{mol})$ & $\Delta \mathrm{H}(\mathrm{kJ} / \mathrm{mol})$ & $\Delta \mathrm{G}(\mathrm{kJ} / \mathrm{mol})$ \\
\hline$\alpha \alpha, \alpha \alpha$ & +10.92 & +2.19 & +5.63 & -3.82 \\
$\alpha \alpha, \alpha \beta$ & +24.75 & +14.40 & +18.89 & +5.61 \\
$\alpha \alpha, \beta \alpha$ & +25.13 & +11.92 & +17.23 & +3.65 \\
$\alpha \alpha, \beta \beta$ & 0.00 & 0.00 & 0.00 & 0.00 \\
$\alpha \beta, \alpha \beta$ & +23.02 & +24.73 & +23.19 & +22.18 \\
$\beta \alpha, \alpha \beta$ & +26.99 & +20.35 & +26.18 & +17.29 \\
$\beta \alpha, \beta \beta$ & +24.56 & +31.25 & +30.32 & +35.51 \\
$\mathrm{~T} 1$ & +32.47 & +28.61 & +24.97 & +21.89 \\
$\mathrm{~T} 2$ & 0.00 & 0.00 & 0.00 & 0.00 \\
$\mathrm{~T} 3$ & +44.11 & +43.98 & +35.03 & +35.83 \\
$\mathrm{~T} 4$ & +27.61 & +27.62 & +25.52 & +25.74 \\
$\mathrm{~T} 5$ & +30.87 & +34.28 & +35.09 & +35.03 \\
$\mathrm{~T} 6$ & +37.35 & +39.18 & +34.94 & +37.49 \\
$\mathrm{~T} 7$ & +32.69 & +33.53 & +38.69 & +37.84 \\
$\mathrm{~T} 8$ & +54.36 & +64.94 & +62.42 & +74.11 \\
\hline
\end{tabular}
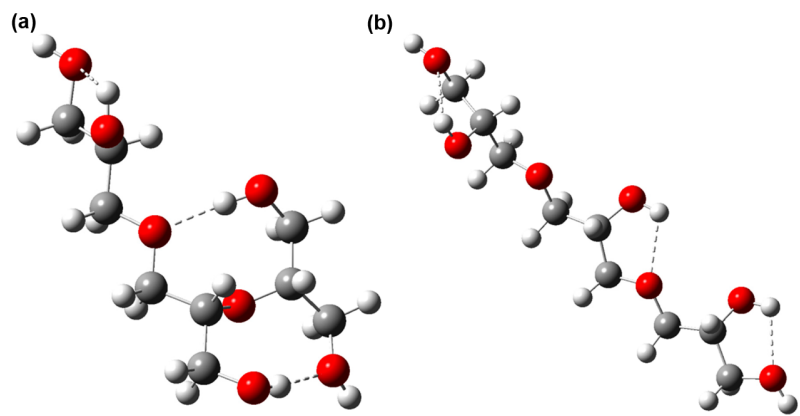

Figure 4. Optimum structures of the (a) $\alpha \alpha, \beta \beta$-triglycerol and (b) $\alpha \alpha, \alpha \alpha$-triglycerol which are the most stable triglycerols in the gas and aqueous phases, respectively.

the most stable conformers in the gas phase.

The $\alpha \alpha, \beta \beta$-triglycerol and $\alpha \alpha, \alpha \alpha$-triglycerol are the most stable acyclic triglycerol in the gas and aqueous phases, respectively. Optimum structures of the $\alpha \alpha, \beta \beta$-triglycerol and $\alpha \alpha, \alpha \alpha$-triglycerol are shown in Fig. 4.

The stability of the $\alpha \alpha, \beta \beta$-triglycerol and $\alpha \alpha, \alpha \alpha$-triglycerol can be attributed to hydrogen bonds which are shown by dotted lines in Fig. 4. However, the $\alpha \alpha, \alpha \alpha$-triglycerol is more stable than $\alpha \alpha, \beta \beta$-triglycerol in the aqueous phase. In the aqueous phase the ability of the linear $\alpha \alpha, \alpha \alpha$-triglycerol to interact to water molecules through hydrogen bonds is more than $\alpha \alpha, \beta \beta$-triglycerol with cage structure. In the case of $\alpha \alpha, \alpha \alpha$-triglycerol, all "O" and " $\mathrm{H}$ " atoms are exposed to water molecules while some of these atoms in the $\alpha \alpha, \beta \beta$-triglycerol are covered by other atoms.

Dehydration of acyclic triglycerols produces the corre- 
<smiles>OCC(O)COCC1COC(CO)CO1</smiles>

T1<smiles>OCC(CO)OCC1COC(CO)CO1</smiles>

T3<smiles>OCC1COCC(OC(CO)CO)CO1</smiles>

T5<smiles>OCC(CO)OC1COCC(O)COC1</smiles>

T7

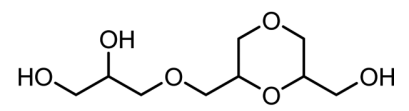

T2<smiles>OCC(O)COC1COCC(CO)OC1</smiles>

T4<smiles>OCC(O)COC1COCC(O)COC1</smiles>

T6

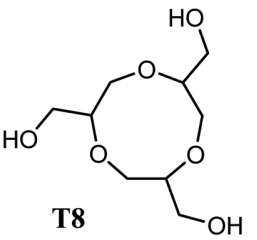

Figure 5. Some of the possible isomers of cyclic triglycerol. The nomination (T1-T8) is arbitrary.

sponding cyclic triglycerols. The cyclic triglycerols can form hexagonal to nonagonal rings. Fig. 5 shows 8 isomers of mono-cyclic triglycerols (T1-T6). From Table 3, the T2 conformer with hexagonal ring is the most stable cyclic triglycerols. In general, the stability of cyclic oligomers decreases as the size of their rings increases; therefore the triglycerol with nonagonal ring is the least stable both in the gas and aqueous phases.

The dehydration reaction is a kind of cyclization reactions in which a water molecule is released. Gibbs free energies, $\Delta \mathrm{G}$, and enthalpies, $\Delta \mathrm{H}$, of the dehydration of the acyclic diglycerols and triglycerols are tabulated in Table 4. Some of the cyclic oligomers can be produced from two acyclic oligomers whose reactions have different $\Delta \mathrm{G}$ and $\Delta \mathrm{H}$. Almost, all of the cyclization reactions of diglycerols and triglycerols are endothermic $(\Delta \mathrm{H}>0)$ while they have negative Gibbs free energies. In addition, the reactions are less endothermic when occur in the aqueous phase; therefore dehydration of the glycerol oligomers during their cyclization is more feasible in aqueous phase, thermodynamically.

Successive oligomerization of glycerol produces different isomers of tetraglycerol. In Table 5 the enthalpy and Gibbs free energy of 23 tetraglycerol isomers are tabulated. All energies are given relative to $\alpha \alpha-\alpha \alpha-\beta \beta$ tetraglycerol energy which is the most stable conformer in the gas phase.

The stability of $\alpha \alpha-\alpha \alpha-\beta \beta$ tetraglycerol in the gas phase
Table 4. Gibbs free energies, $\Delta \mathrm{G}$, and enthalpies, $\Delta \mathrm{H}$, of the dimers and trimers cyclization reactions of glycerol

\begin{tabular}{lrrrr}
\hline & \multicolumn{2}{c}{ Gas phase } & \multicolumn{2}{c}{ Aqueous phase } \\
\cline { 2 - 5 } Cyclization reaction & \multicolumn{1}{c}{$\Delta \mathrm{H}$} & \multicolumn{1}{c}{$\Delta \mathrm{G}$} & $\Delta \mathrm{H}$ & \multicolumn{1}{c}{$\Delta \mathrm{G}$} \\
& $(\mathrm{kJ} / \mathrm{mol})$ & $(\mathrm{kJ} / \mathrm{mol})$ & $(\mathrm{kJ} / \mathrm{mol})$ & $(\mathrm{kJ} / \mathrm{mol})$ \\
\hline$\alpha \beta$-diglycerol $\rightarrow \mathrm{D} 1+\mathrm{H}_{2} \mathrm{O}$ & +31.54 & -8.58 & +14.11 & -26.04 \\
$\alpha \alpha$-diglycerol $\rightarrow \mathrm{D} 2+\mathrm{H}_{2} \mathrm{O}$ & +19.15 & -14.20 & +14.00 & -19.40 \\
$\beta \beta$-diglycerol $\rightarrow \mathrm{D} 2+\mathrm{H}_{2} \mathrm{O}$ & +3.91 & -36.62 & -3.28 & -47.00 \\
$\alpha \alpha$-diglycerol $\rightarrow \mathrm{D} 3+\mathrm{H}_{2} \mathrm{O}$ & +27.39 & -4.59 & +18.83 & -11.62 \\
$\alpha \beta$-diglycerol $\rightarrow \mathrm{D} 3+\mathrm{H}_{2} \mathrm{O}$ & +21.99 & -15.80 & +12.73 & -23.96 \\
$\alpha \alpha$-diglycerol $\rightarrow \mathrm{D} 4+\mathrm{H}_{2} \mathrm{O}$ & +12.65 & -15.22 & +11.66 & -17.46 \\
$\alpha \alpha, \alpha \beta$-triglycerol $\rightarrow \mathrm{T} 1+\mathrm{H}_{2} \mathrm{O}$ & +13.81 & -20.06 & +1.88 & -29.79 \\
$\alpha \alpha, \beta \alpha$-triglycerol $\rightarrow \mathrm{T} 1+\mathrm{H}_{2} \mathrm{O}$ & +13.17 & -17.82 & +3.10 & -28.28 \\
$\alpha \alpha, \alpha \alpha$-triglycerol $\rightarrow \mathrm{T} 2+\mathrm{H}_{2} \mathrm{O}$ & -6.42 & -38.18 & -10.19 & -42.61 \\
$\alpha \alpha, \beta \beta$-triglycerol $\rightarrow \mathrm{T} 2+\mathrm{H}_{2} \mathrm{O}$ & +8.60 & -31.74 & -0.007 & -41.86 \\
$\beta \alpha, \alpha \beta$-triglycerol $\rightarrow \mathrm{T} 3+\mathrm{H}_{2} \mathrm{O}$ & +22.66 & -11.18 & +4.17 & -28.01 \\
$\alpha \beta, \alpha \beta$-triglycerol $\rightarrow \mathrm{T} 3+\mathrm{H}_{2} \mathrm{O}$ & +30.03 & -12.15 & +10.72 & -29.33 \\
$\alpha \alpha, \beta \alpha$-triglycerol $\rightarrow \mathrm{T} 4+\mathrm{H}_{2} \mathrm{O}$ & +6.37 & -20.75 & +2.18 & -25.90 \\
$\alpha \beta, \alpha \beta$-triglycerol $\rightarrow \mathrm{T} 4+\mathrm{H}_{2} \mathrm{O}$ & +13.92 & -28.13 & +2.13 & -38.50 \\
$\alpha \alpha, \beta \beta$-triglycerol $\rightarrow \mathrm{T} 5+\mathrm{H}_{2} \mathrm{O}$ & +37.75 & +0.80 & +34.07 & -7.85 \\
$\beta \alpha, \beta \beta$-triglycerol $\rightarrow \mathrm{T} 5+\mathrm{H}_{2} \mathrm{O}$ & +16.00 & -27.63 & +6.10 & -41.01 \\
$\alpha \alpha, \beta \alpha$-triglycerol $\rightarrow \mathrm{T} 6+\mathrm{H}_{2} \mathrm{O}$ & +15.22 & -10.08 & +10.59 & -15.14 \\
$\alpha \alpha, \beta \beta$-triglycerol $\rightarrow \mathrm{T} 7+\mathrm{H}_{2} \mathrm{O}$ & +40.88 & +1.37 & +38.39 & -4.34 \\
$\alpha \beta, \alpha \beta$-triglycerol $\rightarrow \mathrm{T} 8+\mathrm{H}_{2} \mathrm{O}$ & +36.07 & +4.60 & +34.42 & +5.25 \\
\hline
\end{tabular}

Table 5. The enthalpy and Gibbs free energy of the acyclic tetraglycerols relative to the $\alpha \alpha, \alpha \alpha, \beta \beta$-tetraglycerol conformer

\begin{tabular}{lrrrr}
\hline \multirow{2}{*}{ Tetramer } & \multicolumn{2}{c}{ Gas phase } & \multicolumn{2}{c}{ Aqueous phase } \\
\cline { 2 - 5 } & $\Delta \mathrm{H}(\mathrm{kJ} / \mathrm{mol})$ & $\Delta \mathrm{G}(\mathrm{kJ} / \mathrm{mol})$ & $\Delta \mathrm{H}(\mathrm{kJ} / \mathrm{mol})$ & $\Delta \mathrm{G}(\mathrm{kJ} / \mathrm{mol})$ \\
\hline$\alpha \alpha, \alpha \alpha, \alpha \alpha$ & +3.82 & +4.99 & -2.71 & -11.07 \\
$\alpha \alpha, \alpha \alpha, \alpha \beta$ & +15.26 & +6.28 & +8.92 & -1.78 \\
$\alpha \alpha, \alpha \alpha, \beta \alpha$ & +17.03 & +7.74 & +10.23 & +0.24 \\
$\alpha \alpha, \alpha \alpha, \beta \beta$ & 0.00 & +0.00 & 0.00 & 0.00 \\
$\alpha \alpha, \alpha \beta, \alpha \alpha$ & +21.47 & +13.04 & +10.80 & +1.56 \\
$\alpha \alpha, \alpha \beta, \alpha \beta$ & +22.74 & +18.95 & +14.61 & +12.31 \\
$\alpha \alpha, \beta \alpha, \alpha \alpha$ & +21.27 & +11.11 & +9.56 & -0.33 \\
$\alpha \alpha, \beta \alpha, \alpha \beta$ & +40.45 & +35.94 & +31.20 & +30.25 \\
$\alpha \alpha, \beta \alpha, \beta \alpha$ & +44.80 & +49.11 & +27.41 & +33.98 \\
$\alpha \alpha, \beta \alpha, \beta \beta$ & +58.77 & +49.42 & +50.50 & +44.38 \\
$\alpha \alpha, \beta \beta, \alpha \alpha$ & +17.61 & +18.69 & +9.50 & +7.63 \\
$\alpha \alpha, \beta \beta, \alpha \beta$ & +32.93 & +35.20 & +25.83 & +30.55 \\
$\alpha \beta, \alpha \alpha, \alpha \beta$ & +28.79 & +19.16 & +15.93 & +8.75 \\
$\alpha \beta, \alpha \alpha, \beta \alpha$ & +30.89 & +29.17 & +23.78 & +23.79 \\
$\alpha \beta, \alpha \alpha, \beta \beta$ & +45.19 & +43.84 & +34.82 & +31.98 \\
$\alpha \beta, \alpha \beta, \alpha \beta$ & +42.08 & +37.15 & +29.87 & +26.29 \\
$\beta \alpha, \alpha \alpha, \alpha \beta$ & +28.98 & +20.68 & +18.97 & +15.04 \\
$\beta \alpha, \alpha \alpha, \beta \beta$ & +53.26 & +48.44 & +39.17 & +40.48 \\
$\beta \alpha, \alpha \beta, \alpha \beta$ & +27.08 & +27.27 & +26.71 & +25.07 \\
$\beta \alpha, \beta \beta, \alpha \beta$ & +22.92 & +35.25 & +24.87 & +37.50 \\
$\beta \beta, \alpha \alpha, \alpha \beta$ & +5.87 & +11.06 & +3.04 & +7.43 \\
$\beta \beta, \alpha \alpha, \beta \beta$ & +5.48 & +13.00 & +10.30 & +18.55 \\
$\beta \beta, \alpha \beta, \alpha \beta$ & +43.53 & +43.09 & +45.37 & +44.55 \\
\hline & & & &
\end{tabular}


(a)

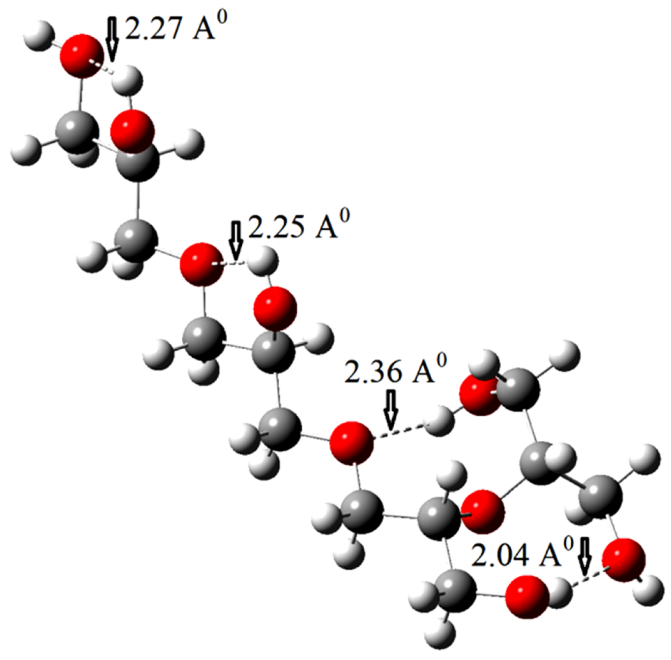

(b)

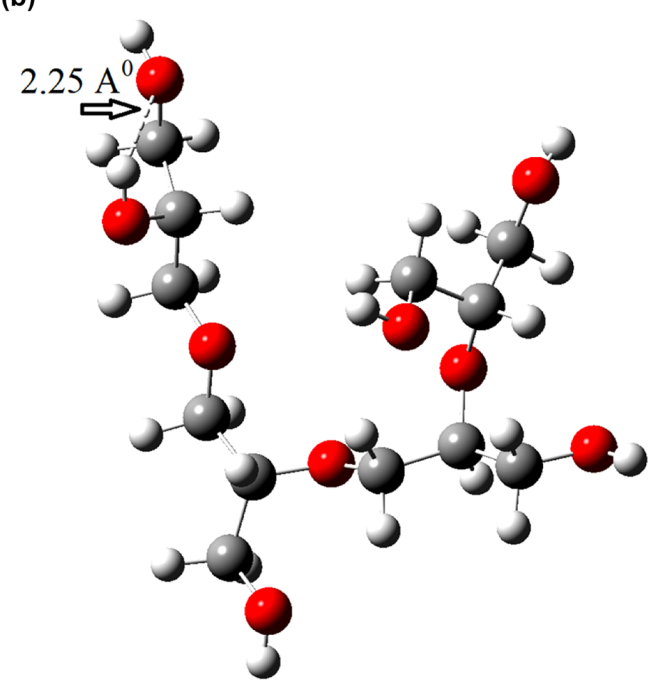

Figure 6. Optimum structures of (a) $\alpha \alpha, \alpha \alpha, \beta \beta$-tetraglycerol and (b) $\alpha \alpha, \beta \alpha, \beta \beta$-tetraglycerol which are the most and least stable acyclic tetraglycerols in the gas phase, respectively. Hydrogen bonds are shown by dotted lines.

probably is due to hydrogen bonding interactions which four of these interactions have been shown in Fig. 6. Considering the hydrogen bonding interactions, two octagonal rings are formed in the $\alpha \alpha-\alpha \alpha-\beta \beta$ tetraglycerol structure which an oxygen atom is common between them. Two hydrogen atoms of these rings make hydrogen bonds with bond lengths of 2.36 and $2.04 \mathrm{~A}^{\circ}$. These hydrogen atoms can additionally interact with the common oxygen atom and the structure becomes more stable. The $\alpha \alpha-\beta \alpha-\beta \beta$ structure with only one hydrogen bonding interaction is the least stable tetraglycerol.

In the aqueous phase, the $\alpha \alpha, \alpha \alpha, \alpha \alpha$ and $\beta \beta, \alpha \beta, \alpha \beta-$ tetraglycerol structures are the most and least stable tetramers, respectively. The stability of $\alpha \alpha, \alpha \alpha, \beta \beta$-tetraglycerol in the gas phase is due to intramolecular hydrogen bonds. However, in the aqueous phase, interactions between the tetraglycerol and water molecules play an important role in its stability; therefore, the $\alpha \alpha, \alpha \alpha, \alpha \alpha$-tetraglycerol with linear structure has the most capability for intermolecular hydrogen bonding interaction with water molecules. In the other hand, the $\beta \beta, \alpha \beta, \alpha \beta$-tetraglycerol has a cage structure; hence, diffusion of water into its structure to form the hydrogen bonds is difficult. Although the $\alpha \alpha$, $\beta \alpha, \beta \beta$-tetraglycerol is the least stable tetraglycerol in gas phase, in aqueous medium it can interact with water molecules to form the hydrogen bonds and becomes more stable.

\section{CONCLUSION}

Hydrogen bonding interactions play an important role in the stability of the glycerol oligomers. Linear oligomers are more stable in aqueous phases; because they can interact with water molecules through hydrogen bonds better than non-linear ones. Dehydration of the oligomers which results in formation of cyclic oligomers is endothermic reaction while its $\Delta \mathrm{G}$ is negative. The dehydration reaction is less endothermic in aqueous phase.

Acknowledgments. The publication cost of this paper was supported by the Korean Chemical Society.

\section{REFERENCES}

1. Neumann, W. H. C. Glycerin(e) and its history. In Cosmetic Science and Technology Series 11; Jungermann, E., Sonntag, N. O. V., Eds.; Marcel Dekker, Inc.: New York 1991; Chapter 2, pp 7-14.

2. Martin, A.; Richter, M. Eur. J. Lipid Sci. Technol. 2011, 113, 100-117.

3. Pagliaro, M.; Ciriminna, R.; Kimura, H.; Rossi, M.; Della Pina, C. Angew. Chem., Int. Ed. 2007, 46, 4434-4440.

4. Zheng, Y.; Chen, X.; Shen, Y. Chem. Rev. 2008, 108, 5253-5277.

5. Barrault, J., Jérôme, F. Eur. J. Lipid Sci. Technol. 2008, $110,825-830$.

6. Jérôme, F.; Pouilloux, Y.; Barrault, J. ChemSusChem 2008, 1, 586-613.

7. Behr, A.; Gomes, J. P. Eur. J. Lipid Sci. Technol. 2010, 112, 31-50.

8. Jakobson, G. Fette, Seifen, Anstrichmittel 1986, 88, 101106.

9. Richter, M.; Eckelt, R.; Krisnandi, Y. K.; Martin, A. Chem. Ing. Tech. 2008, 80, 1573-1577. 
10. Barrault, J.; Pouilloux, Y.; Clacens, J. M.; Vanhove, C.; Bancquart, S. Catal. Today 2002, 75, 177-181.

11. Behrens, H.; Mieth, G. Die Nahrung 1984, 28, 815-835.

12. Wittcoff, H.; Roach, J. R.; Miller, S. E. J. Am. Chem. Soc. 1947, 69, 2655-2657.

13. Wittcoff, H.; Roach, J. R.; Miller, S. E. J. Am. Chem. Soc. 1949, 71, 2666-2668.

14. Medeiros, M. A.; Araujo, M. H.; Augusti, R.; de Oliveira, L. C. A.; Lago, R. M. J. Braz. Chem. Soc. 2009, 20, 16671673.

15. Calatayud, M.; Ruppert, A. M.; Weckhuysen, B. M. Chem. Eur. J. 2009, 15, 10864-10870.
16. Ruppert, A. M.; Meeldijk, J. D.; Kuipers, B. W. M.; Ern, B. H.; Weckhuysen, B. M. Chem. Eur. J. 2008, 14, 20162024.

17. Wei, D. Q.; Salahub, D. R. In Combined Quantum Mechanical and Molecular Mechanical Methods, Gao, J., Thompson, M. Eds.; Wiley: New York, 1998; Chapter 11-15.

18. Wei, D. Q.; Proynov, E. I.; Milet, A.; Salahub, D. R. J. Phys. Chem. 2000, 104, 2384.

19. Miertus, S.; Tomasi, J. Chem. Phys. 1982, 65, 239-245.

20. Frisch, M. J.; et al. Gaussian 09, revision A.1.; Gaussian, Inc.: Wallingford, 2009. 